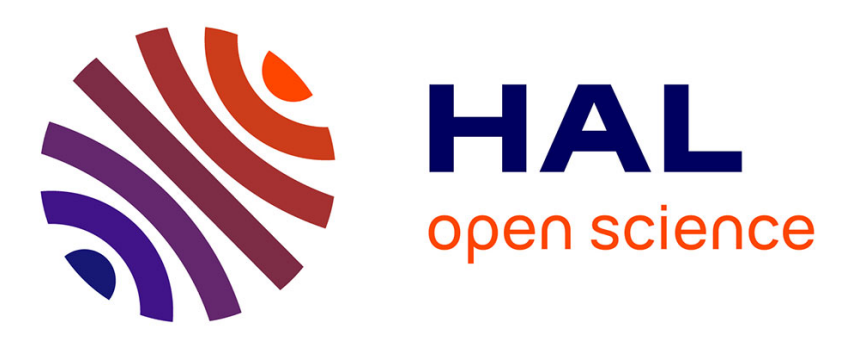

\title{
High-Resolution Two-Field Nuclear Magnetic Resonance Spectroscopy
}

Samuel F Cousin, Cyril Charlier, Pavel Kadeřávek, Thorsten Marquardsen, Jean-max Tyburn, Pierre-alain Bovier, Simone Ulzega, Thomas Speck, Dirk

Wilhelm, Frank F Engelke, et al.

\section{To cite this version:}

Samuel F Cousin, Cyril Charlier, Pavel Kadeřávek, Thorsten Marquardsen, Jean-max Tyburn, et al.. High-Resolution Two-Field Nuclear Magnetic Resonance Spectroscopy. Physical Chemistry Chemical Physics, 2016, 18, pp.33187-33194. 10.1039/C6CP05422F . cea-01393871

\section{HAL Id: cea-01393871 https://hal-cea.archives-ouvertes.fr/cea-01393871}

Submitted on 7 Dec 2016

HAL is a multi-disciplinary open access archive for the deposit and dissemination of scientific research documents, whether they are published or not. The documents may come from teaching and research institutions in France or abroad, or from public or private research centers.
L'archive ouverte pluridisciplinaire HAL, est destinée au dépôt et à la diffusion de documents scientifiques de niveau recherche, publiés ou non, émanant des établissements d'enseignement et de recherche français ou étrangers, des laboratoires publics ou privés. 


\title{
High-Resolution Two-Field Nuclear Magnetic Resonance Spectroscopy
}

\author{
Samuel F. Cousin, ${ }^{\mathrm{a}, \mathrm{b}, / /}$ Cyril Charlier, ${ }^{\mathrm{a}, \mathrm{b}, / /,+}{ }^{+}$Pavel Kadeřávek, ${ }^{\mathrm{a}, \mathrm{b}}$ Thorsten Marquardsen, ${ }^{\mathrm{c}}$ Jean-Max \\ Tyburn, ${ }^{d}$ Pierre-Alain Bovier, ${ }^{e}$ Simone Ulzega, ${ }^{e}, \S$ Thomas Speck, ${ }^{e}$ Dirk Wilhelm, ${ }^{e, n}$ Frank Engelke, ${ }^{c}$ \\ Werner Maas, ${ }^{f}$ Dimitrios Sakellariou, ${ }^{\mathrm{g}}$ Geoffrey Bodenhausen, ${ }^{\mathrm{a}, \mathrm{b}}$ Philippe Pelupessy, ${ }^{\mathrm{a}, \mathrm{b}}$ Fabien \\ Ferrage ${ }^{a, b, *}$
}

\begin{abstract}
Nuclear Magnetic Resonance (NMR) is a ubiquitous branch of spectroscopy that can explore matter at the scale of the atom. Significant improvements in sensitivity and resolution have been driven by a steady increase of static magnetic field strengths. However, some properties of nuclei may be more favourable at low magnetic fields. For example, transverse relaxation due to chemical shift anisotropy increases sharply at higher magnetic fields leading to line-broadening and inefficient coherence transfers. Here, we present a two-field NMR spectrometer that permits the application of rf-pulses and acquisition of NMR signals in two magnetic centres. Our prototype operates at $14.1 \mathrm{~T}$ and $0.33 \mathrm{~T}$. The main features of this system are demonstrated by novel NMR experiments, in particular a proof-of-concept correlation between zeroquantum coherences at low magnetic field and single quantum coherences at high magnetic field, so that high resolution can be achieved in both dimensions, despite a ca. $10 \mathrm{ppm}$ inhomogeneity of the low field centre. Two-field NMR spectroscopy offers the possibility to circumvent the limits of high magnetic fields, while benefiting from their exceptional sensitivity and resolution. This approach opens new avenues for NMR above $1 \mathrm{GHz}$.
\end{abstract}

\section{Introduction}

Nuclear Magnetic Resonance (NMR) is routinely used to explore matter in a wide range of research fields. The development of NMR spectrometers at very high magnetic fields, ${ }^{1}$ along with creative methodological developments, ${ }^{2-7}$ has allowed the study of molecules and materials of increasing complexity. ${ }^{8-13}$ The sensitivity and resolution of most NMR experiments increase with the magnetic field. However, some NMR properties become less favourable at high magnetic fields. Transverse relaxation may become excessive at high magnetic fields. In particular, transverse relaxation rates increase quadratically with the magnetic field under fast chemical exchange or relaxation by chemical shift anisotropy (CSA), which is the main relaxation mechanism for carbonyl carbon-13 14,15 or phosphorus-31 ${ }^{16}$ nuclei. Fast transverse relaxation results in broad lines and inefficient coherence transfers. Increasing the magnetic field may thus lead to lower resolution and sensitivity. Radio-frequency ( $\mathrm{rf}$ ) pulses may also be too weak to allow broadband excitation, decoupling or coherence transfer. Can we design an NMR approach that benefits from the sensitivity and resolution of high magnetic fields and that permits the control and evolution of spin systems at low magnetic fields within the same experiment? Several groups have developed experiments where a sample is exposed to two or more magnetic fields to investigate magnetic-field dependent properties, such as zero ${ }^{17,} 18$ and ultra-low field ${ }^{19}$ NMR or field-cycling experiments. ${ }^{20-22}$ Fast field cycling experiments can be performed by two different approaches. The first option is to rapidly switch the electric current in an electromagnet to change the magnetic field after polarization to a lower magnetic field for relaxation. The magnetic field is then changed again to detect the NMR signal at a higher field. ${ }^{20}, 23$ Magnetic-field dependent relaxation rates have provided information on molecular motions in a host of systems, such as water, 24,25 water in solutions of contrast agents, ${ }^{26-28}$ porous media, ${ }^{29}, 30$ or motions in synthetic polymers ${ }^{31}$ or biomolecules. ${ }^{32-36}$ The second approach consists in physically moving the sample in the fringe field of a highfield magnet $\left(\mathrm{B}_{0}{ }^{\mathrm{HF}}\right)$ to reach a lower field position $\left(\mathrm{B}_{0}{ }^{\mathrm{LF}}\right)$. One can also shuttle the sample between two magnets. ${ }^{37}$ This can be achieved either by moving the entire NMR probe, ${ }^{38,} 39$ or only the sample with mechanical ${ }^{22,40}$ or pneumatic systems. ${ }^{21}$, ${ }^{36}$ Such shuttle systems have been employed in the frame of dynamic nuclear polarization (DNP). ${ }^{41}$

Here, we present in detail a two-field NMR spectrometer designed to manipulate and observe spin systems in two magnetic centres with significantly different magnetic fields. ${ }^{42}$ This system allows the measurement of properties that are more favourable at low magnetic fields, while benefiting from the sensitivity and resolution of a superconducting high-field magnet. In our prototype, a fairly homogeneous magnetic field at $0.33 \mathrm{~T}$ has been obtained by engineering a plateau in the stray field of a superconducting $14.1 \mathrm{~T}$ magnet $(600 \mathrm{MHz}$ proton resonance). Both magnetic centres are equipped with triple-resonance probes with a single-axis gradient. The samples can be transferred between the two fields by a pneumatic shuttle system. ${ }^{36}$ Here, we describe the technical features of this system, and introduce a series of two-field NMR experiments, including a two-field heteronuclear singlequantum coherence experiment (2F-HSQC). In spite of the low resolution in the indirect dimension, some key features are accessible, such as multiplet patterns due to scalar couplings. Furthermore, we introduce a two-field homonuclear zeroquantum/single quantum correlation experiment (2FINAZEQUATE) that can provide high-resolution spectra in both dimensions despite the moderate magnetic field inhomogeneities of the low-field magnetic centre. 


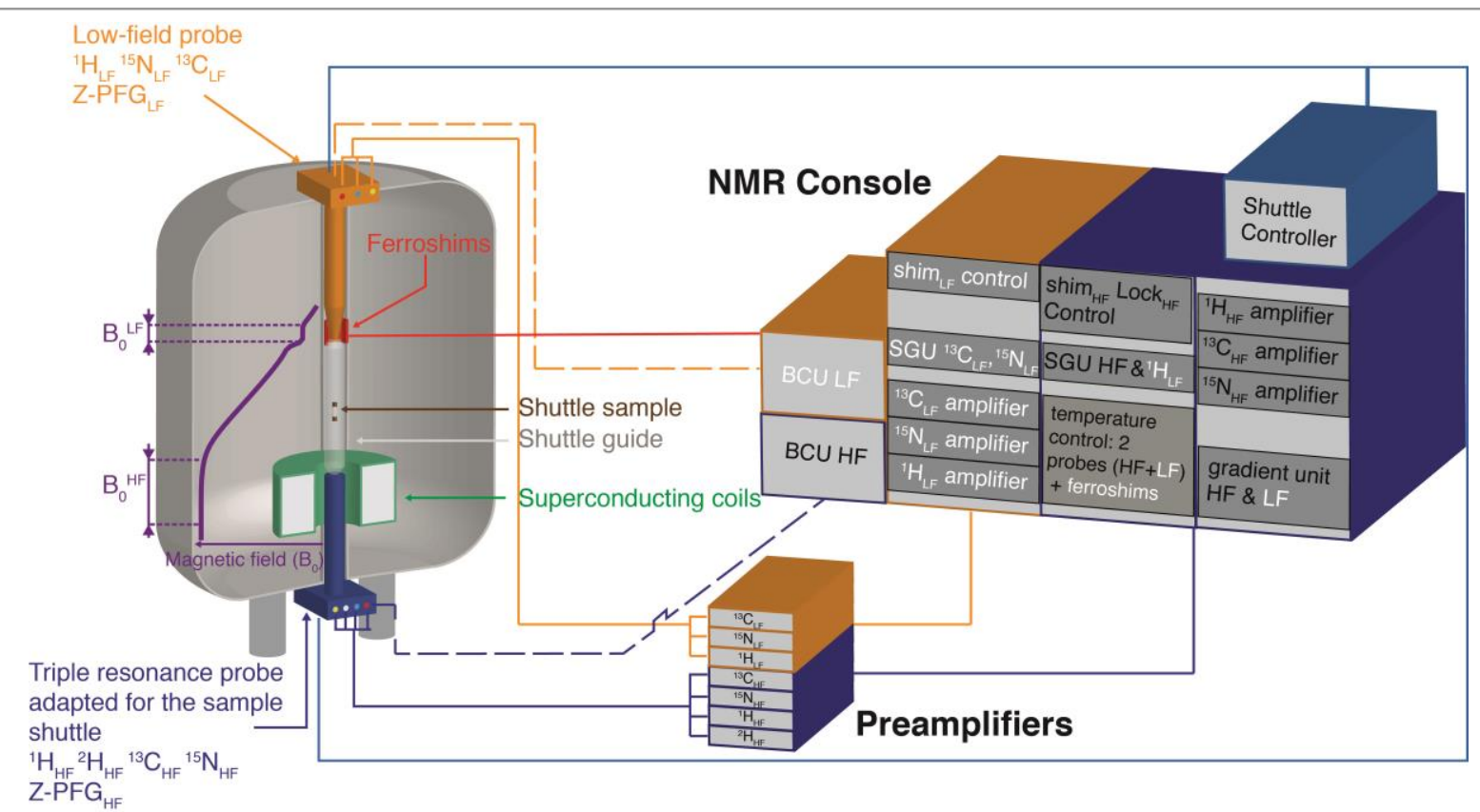

Figure 1. Schematic representation of the two-field NMR spectrometer. The subscripts $L F$ and HF distinguish channels dedicated to the low-field centre at $0.33 \mathrm{~T}$ and the highfield centre at $14.1 \mathrm{~T}$. The components of the $600 \mathrm{MHz}$ spectrometer are shown in blue with black letters, the components designed for the low-field centre are shown in orange with white letters. Soft magnetic materials (ferroshims) are shown in red. The signal generating units (SGUs) can generate radiofrequency pulses at six frequencies. A deuterium channel allows for field-frequency locking at high field.

\section{Materials: Two-field NMR spectrometer}

The two-field NMR spectrometer is based on a commercial NMR spectrometer operating at $14.1 \mathrm{~T}$ augmented by a series of accessories (Figure 1). (i) A pneumatic sample shuttle apparatus, ${ }^{36}$ (ii) devices to obtain a plateau at $0.33 \mathrm{~T}$ in the stray field of the superconducting magnet, including rings of soft magnetic material (ferroshims), a set of roomtemperature shim coils, and strips of $\mu$-metal, (iii) a low-field triple resonance probe operating at $14.1,3.52$ and $1.42 \mathrm{MHz}$ for ${ }^{1} \mathrm{H},{ }^{13} \mathrm{C}$ and ${ }^{15} \mathrm{~N}$ respectively at the $0.33 \mathrm{~T}$, equipped to generate single-axis pulsed field gradients, (iv) systems for generating and amplifying rf-pulses at low frequencies. The TopSpin software was modified to perform experiments with six rf channels in two different probes. The individual components are described in detail below.

\section{Ferroshims}

Diverse systems can be used to obtain a plateau of magnetic field in the stray field of a high-field magnet. ${ }^{37,} 43,44$ Here, five rings of a soft magnetic alloy $\mathrm{Ni}_{48} \mathrm{Fe}_{52}$ have been combined to generate a plateau of magnetic field at $0.33 \mathrm{~T}$ in the stray field (Figure 2). An earlier design included only three rings. ${ }^{44,} 45$ The temperature of the ferroshim rings is regulated (see below) to enhance the stability of the magnetic field. Strips of $\mu$-metal (called shim foils) and a set of electric room-temperature shim coils have improved the homogeneity. This combination of devices leads to a residual inhomogeneity of the magnetic field of about $10 \mathrm{ppm}$ over a length of $2 \mathrm{~cm}$.
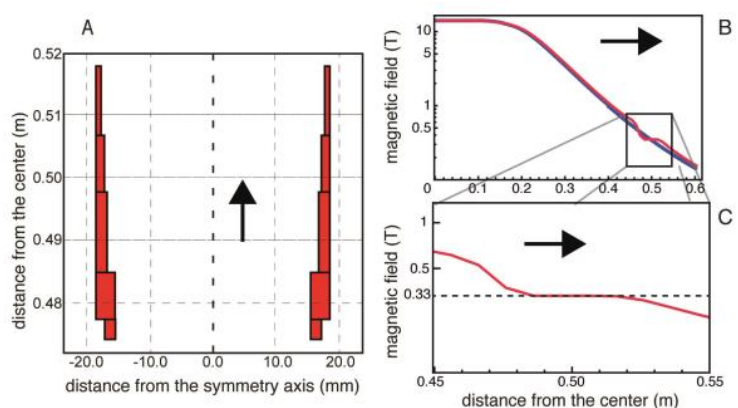

Figure 2. (A) Ferroshims designed to compensate the inhomogeneity of the magnetic field positioned with respect to the distance from the magnetic centre at $14.1 \mathrm{~T}$. (B) Measured magnetic field profile ${ }^{36}$ along the axis of the bore of a $14.1 \mathrm{~T}$ superconducting magnet between the centre of the magnet to $0.6 \mathrm{~m}$ above this centre: without ferroshims (blue) and with ferroshims (red, simulated). (C) Magnetic field profile close to the low-field magnetic centre at $0.33 \mathrm{~T}$.

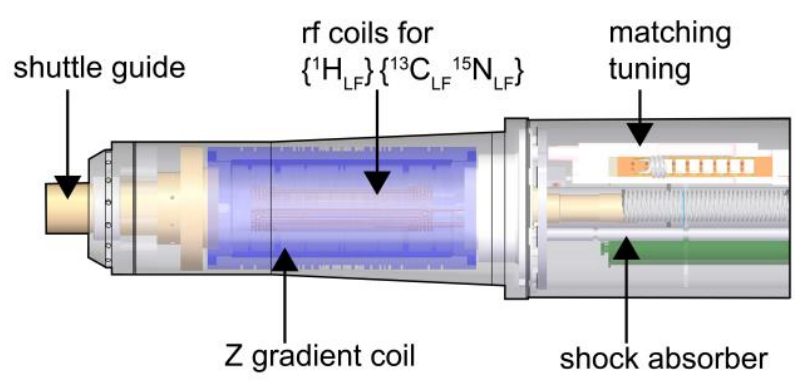

Figure 3. Low-field probe designed for rf pulses at $14.1,3.52$ and $1.42 \mathrm{MHz}$ for ${ }^{1} \mathrm{H},{ }^{13} \mathrm{C}$ and ${ }^{15} \mathrm{~N}$, respectively in the $0.33 \mathrm{~T}$ magnetic centre.

\section{Probes}

The high-field triple-resonance probe has been described previously. ${ }^{36}$ The low-field probe is also designed to isolate rf components from vibrations caused by the motions of the 
sample. The triple-resonance low-field probe consists of two coils: the inner coil has three windings with saddle-coil geometry. It is optimized for protons at $14.1 \mathrm{MHz}$. The outer coil has seven windings and a saddle coil geometry. Its resonance frequencies are optimized for both carbon-13 (3.52 $\mathrm{MHz}$ ) and nitrogen-15 (1.42 MHz) frequencies. In addition, this probe is equipped with a coil to generate z-axis pulsed field gradients (up to $10 \mathrm{G} / \mathrm{cm}$ ). The low-field probe does not comprise a deuterium coil. The homogeneity and stability of the low magnetic field can be monitored by proton NMR.

\section{Low-field spectrometer}

The system is shown in Figure 4. State-of-the-art Avance III HD NMR spectrometers can operate down to $6 \mathrm{MHz}$. An additional low-frequency signal-generating unit (SGU) that had originally been designed for mass spectroscopy has therefore been used to generate radiofrequency pulses with controlled phases and amplitudes at frequencies in the range $2.5 \mathrm{kHz}$ to $6 \mathrm{MHz}$. Two low-frequency $200 \mathrm{~W}$ amplifiers (1020L Power Amplifier from Electronics \& Innovation) are used for ${ }^{13} \mathrm{C}_{\mathrm{LF}}$ and ${ }^{15} \mathrm{~N}_{\mathrm{LF}}$ channels. The linearity of these amplifiers is enhanced by correction tables for the amplitudes (but not for the phases) similar to standard practice for high-frequency amplifiers. These correction tables provide excellent linearity for nitrogen-15 and satisfactory linearity for carbon-13 (supporting information). Up to six channels can be used in any given experiment. Finally, two channels of a GREAT3/10 gradient amplifier, which was originally designed for a three-axis gradient system, are employed to generate pulsed field gradients (PFG's) along the z-axis of the low- and high-field probes.

\section{Sample shuttle}

This part was originally designed for high-resolution relaxometry. ${ }^{28,} 36$ The only modification is the tube that guides the sample shuttle in between the two probes, called shuttle guide. A plastic piston-like system is used here, where a spring ensures a tight fit of the shuttle guide between the top of the high-field probe and the bottom of the low-field probe. Typical shuttle transfer delays are $100 \mathrm{~ms}$ for motions between the high- and low-field centres. Such transfer delays correspond to an overpressure $c a$. 0.3 bar and an under-pressure $c a$. -0.25 $\mathrm{Pa}$, that are both well below the extreme settings allowed for the system.

\section{Additional units}

An auxiliary Bruker Smart Magnet System (BSMS) is used in order to control the homogeneity of the magnetic field at the low-field centre. This unit controls a set of 20 roomtemperature electric shims (BOSS1). There is no fieldfrequency lock at the low-field centre. A second two-channel Variable Temperature Unit (VTU) regulates independently the temperatures of the ferroshims and the low-field probe. The nitrogen used for the temperature regulation of the ferroshims is heated above room temperature so that the ferroshims remain at $300.2 \pm 0.1 \mathrm{~K}$. The nitrogen used to regulate the temperature of the low-field probe is cooled to about $263 \mathrm{~K} \mathrm{(-}$ $\left.10^{\circ} \mathrm{C}\right)$ by a Bruker Control Unit (BCU) and heated to the desired temperature by a resistance in the low-field probe. The shuttle controller uses nitrogen gas at 5 to 6 bar and an internal vacuum pump.

\section{Sample preparation}

The sample shuttle ${ }^{36}$ consists of four pieces of amorphous quartz glued together. The sample tube contains about $110 \mu \mathrm{L}$ of solution; the active volume within the rf coils which cover about $20 \mathrm{~mm}$ is $60 \mu \mathrm{L}$. This study used $1 \mathrm{M}$ solution of ${ }^{13} \mathrm{C}-{ }^{15} \mathrm{~N}$ labelled glycine in $97 \% \mathrm{D}_{2} \mathrm{O}$, and a $1 \mathrm{M}$ solution of sucrose at natural abundance in $\mathrm{D}_{2} \mathrm{O}$.

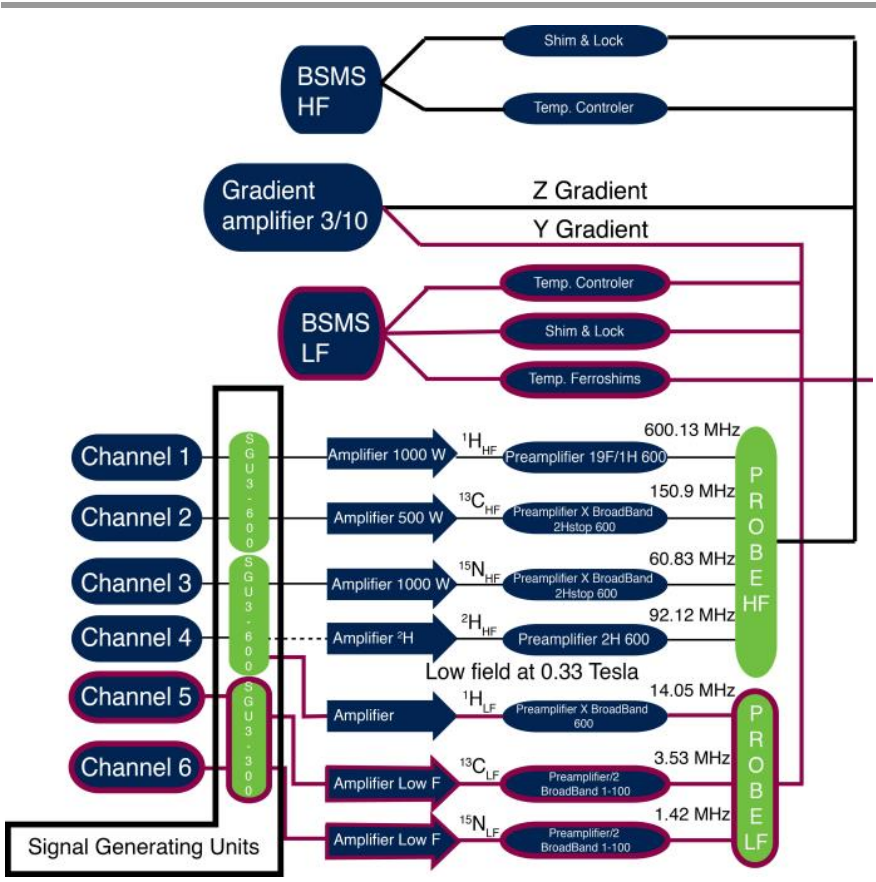

Figure 4. Design of the two-field NMR spectrometer. Red lines indicate devices and connections added to those found in a conventional high-field spectrometer.

\section{Results and discussion}

\section{Homogeneity of the low-field magnetic centre}

Obtaining a sufficiently homogeneous plateau in the stray field of a superconducting magnet is a challenge. The variation of the magnetic field along the $20 \mathrm{~mm}$ active length of the sample was determined from measurements of the stray field ${ }^{36}$ to be $67 \mathrm{mT}$ at $0.33 \mathrm{~T}$, that is $2.03 \times 10^{5} \mathrm{ppm}$ before compensation. Figure 5.B shows a typical proton spectrum recorded for a sample of sucrose in $\mathrm{D}_{2} \mathrm{O}$ at $0.33 \mathrm{~T}$ using both ferroshims and electric shims. The sensitivity of the experiment was enhanced by polarization at $14.1 \mathrm{~T}$ (Figure 5.A). The full width at half height is $10 \mathrm{ppm}$, which corresponds to a dramatic improvement of the homogeneity by a factor $\sim 10^{4}$. Such homogeneity was achieved reproducibly on several samples with adjustment of the shim currents limited to the main shim coils, with $z, z^{2}$, and $z^{3}$ geometries. 


\section{Radiofrequency pulses in the low-field centre}

Nutation experiments have been performed at $0.33 \mathrm{~T}$ for all channels (i.e., ${ }^{1} \mathrm{H},{ }^{13} \mathrm{C},{ }^{15} \mathrm{~N}$ ) in order to characterize the amplitudes and homogeneities of all radio-frequency fields in the low-field centre (Figure 6). The sensitivity was enhanced by allowing the polarization to build up in high field and by observing the signals in the high field. The sample is transferred to the low field where radiofrequency pulses with variable durations are applied. The transverse components of the magnetization are suppressed by gradients during the transfer from low to high field. The remaining longitudinal polarization after the radiofrequency pulse at low field is detected at high field after a $90^{\circ}$ pulse.

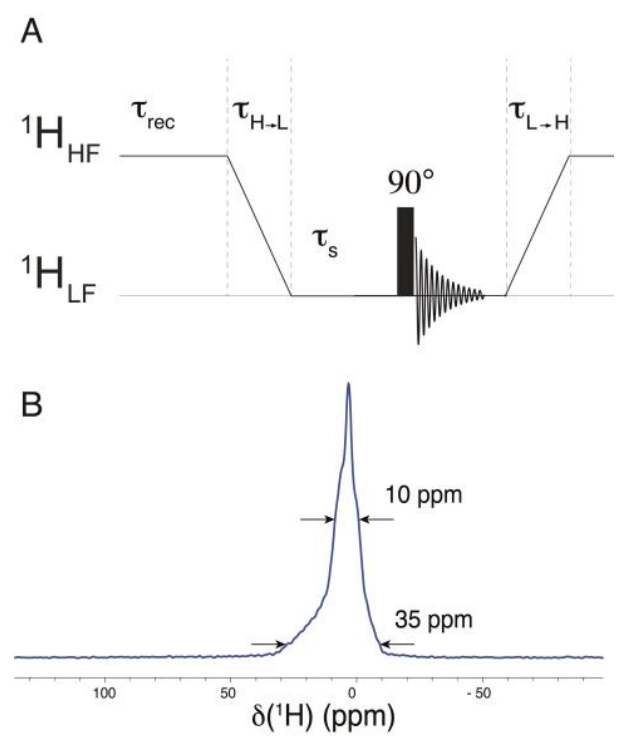

Figure 5. (A) Pulse sequence for obtaining a proton NMR spectrum at $0.33 \mathrm{~T}$. Polarization is allowed to build up at $14.1 \mathrm{~T}$ during a recovery delay $\tau_{\text {rec }}=5 \mathrm{~s}$. The sample is then transferred to low field during $\tau_{H \rightarrow L}=80 \mathrm{~ms}$. After a stabilization delay $\tau_{\mathrm{s}}$ $=100 \mathrm{~ms}$, a $90^{\circ}$ pulse is applied and the signal is acquired at low field. The sample is transferred back to high field during the delay $\tau_{L \rightarrow H}=80 \mathrm{~ms}$ if several scans need to be recorded. (B) Proton spectrum at $0.33 \mathrm{~T}$ for a sample of $1 \mathrm{M}$ sucrose in $\mathrm{D}_{2} \mathrm{O}$, recorded with a single scan.
A
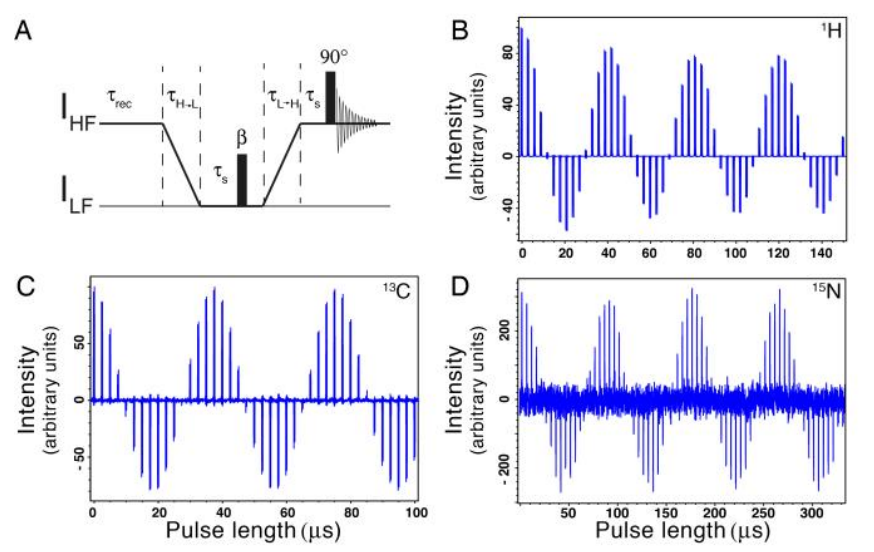

Figure 6. Two-field nutation experiments designed to characterize the three rf fields at low field. (A) Pulse sequence for nutation experiments at low field. The nutation angle 国 was varied in a linear fashion. (B) Nutation on the proton channel at $14.1 \mathrm{MHz}$ with 国 ${ }_{1}^{H} / 2$ 国 $=24.5 \mathrm{kHz}$. (C) Nutation on the carbon-13 channel at $3.52 \mathrm{MHz}$ with ${ }_{1}^{\mathrm{C}} / 2$ ? $=$
$22.5 \mathrm{kHz}$ (D) Nutation on the nitrogen-15 channel at $1.42 \mathrm{MHz}$ with $\mathrm{l}_{1}^{\mathrm{N}} / 2$ ] $=12.5 \mathrm{kHz}$. All experiments have been performed with $1 \mathrm{M}^{13} \mathrm{C}-{ }^{-15} \mathrm{~N}$ labelled glycine in $\mathrm{D}_{2} \mathrm{O}$.

The amplitudes of the rf pulses at low field are comparable or superior to those obtained with the high-field probe. Typical pulse specifications at low field are summarized in Table 1. Thus, $r f$ pulses with exceptional broadband capabilities can be readily obtained at low field. In addition, the homogeneity of rf pulses at low field is excellent, with $I_{900} / I_{180}=80 \pm 2 \%$ for proton, $I_{900} / I_{180}=98 \pm 2 \%$ for carbon-13 and $I_{900} / I_{180}=96 \pm 12$ $\%$ for nitrogen-15, with $I_{900}$ the intensity measured after a $900^{\circ}$ pulse and $/ I_{180}$ the intensity measured after a $180^{\circ}$ pulse. The nutation profiles are all imbalanced (the local minima are not as intense as the local maxima). This is likely due to the effect of longitudinal relaxation during the transfer from the lowfield centre to the high-field centre and the stabilization delay $\tau_{s}$. The imbalance is more pronounced for the nutation on the proton channel. An additional contribution to this imbalance is likely due to the fact the proton coil at low field is slightly smaller than the proton coil in the high-field centre.

Radiofrequency fields for the magnetic centre at $0.33 \mathrm{~T}$

\begin{tabular}{ccccc}
\hline Channel & $\begin{array}{c}\text { Power } \\
(\mathbf{W})\end{array}$ & $\begin{array}{c}\mathbf{9 0}^{\circ} \text { pulse } \\
(\boldsymbol{\mu s})\end{array}$ & $\begin{array}{c}\omega_{\mathbf{1}} / \mathbf{2} \boldsymbol{\pi} \\
(\mathbf{k H z})\end{array}$ & $\mathbf{I}_{\mathbf{9 0 0}} / \mathrm{I}_{\mathbf{1 8 0}}$ \\
\hline${ }^{\mathbf{1}} \mathrm{H}$ & 0.5 & 10.2 & 24.5 & $80 \pm 2 \%$ \\
${ }^{13} \mathrm{C}$ & 100 & 11.1 & 22.5 & $98 \pm 2 \%$ \\
${ }^{15} \mathrm{~N}$ & 50 & 20 & 12.5 & $96 \pm 12 \%$ \\
\hline
\end{tabular}

\section{Two-dimensional two-field correlation experiment}

We introduce two-dimension experiments that provide correlations of chemical shifts recorded at different magnetic fields. A two-field heteronuclear single-quantum coherence experiment (2F-HSQC) was performed to demonstrate the principle of two-dimensional two-field (2D-2F) single-quantum correlation spectroscopy. The original HSQC experiment ${ }^{46}$ was modified to provide a correlation between ${ }^{13} \mathrm{C}$ chemical shifts at low field in the indirect $\omega_{1}$ dimension and ${ }^{1} \mathrm{H}$ chemical shits at high field in the direct $\omega_{2}$ dimension. The pulse sequence is shown in Figure 7. After a recovery delay at high field, the ${ }^{1} \mathrm{H}$ polarisation is transferred to ${ }^{13} \mathrm{C}$ by a modified INEPT sequence ${ }^{47}$ that generates two-spin order $2 \mathrm{C}_{2} \mathrm{H}_{2}$ prior to the transfer of the sample to the low-field centre. An anti-phase coherence $2 \mathrm{C}_{\mathrm{x}} \mathrm{H}_{\mathrm{z}}$ is then allowed to evolve under the chemical shift at low field. The polarization is again stored as a two-spin order $2 \mathrm{C}_{z} \mathrm{H}_{\mathrm{z}}$ while the sample is transferred by a reverse INEPT sequence back to the high-field centre. A proton signal is then detected under ${ }^{13} \mathrm{C}$ composite-pulse decoupling. 


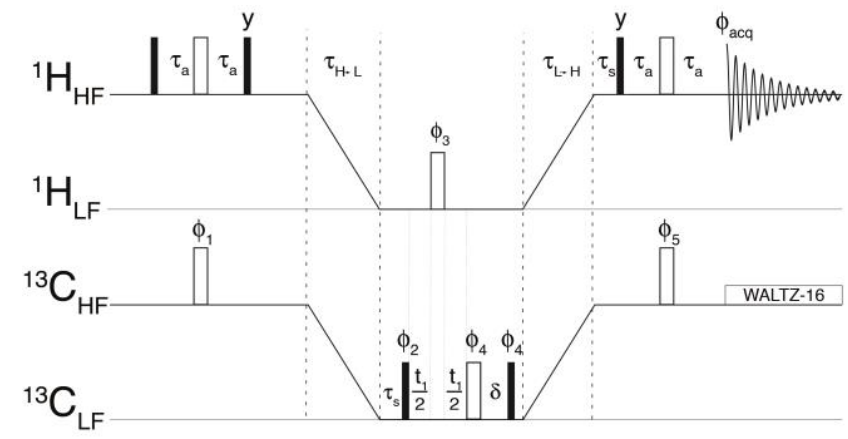

Figure 7. Pulse sequence for the two-field heteronuclear single-quantum coherence (2F-HSQC) experiment. Proton chemical shifts at high field are correlated with carbon13 chemical shifts at low field. Narrow (filled) and wide (open) rectangles represent $90^{\circ}$ and $180^{\circ}$ pulses, respectively. The stabilization delay $\tau_{\mathrm{s}}=100 \mathrm{~ms}$ allows settling of convection currents and vibrations induced by the sample landing. The delay $\delta$ is chosen to obtain an echo for $t_{1}=0$. The transfer of polarization is performed with $\tau_{\text {D }}=$ $1 /\left(4 \mathrm{~J}_{\mathrm{CH}}\right)=1.72 \mathrm{~ms}$. The duration for sample transfer from the high- to low field is

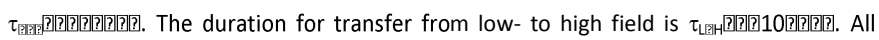
pulses are applied along the $x$-axis of the rotating frame, unless otherwise indicated. The phase cycles are: $\phi_{1}=8\{x\}, 8\{-x\} ; \phi_{2}=x,-x ; \phi_{3}=2\{x\}, 2\{-x\} ; \phi_{4}=4\{x\}, 4\{-x\} ; \phi_{5}=8\{x\}, 8\{-x\} ;$ $\phi_{\text {aca }}=\{x\}, 2\{-x\},\{x\},\{y\}, 2\{-y\},\{y\}$. Composite pulse decoupling during detection was carried with a WALTZ-16 scheme ${ }^{48}$ applied on-resonance to the ${ }^{13} \mathrm{C}^{\alpha}$ spins with an rf amplitude $\omega_{\mathrm{cpd}}^{\mathrm{C}} /(2 \pi)=2.08 \mathrm{kHz}$

The 2F-HSQC spectrum in Figure 8 was obtained with a $1 \mathrm{M}$ sample of ${ }^{13} \mathrm{C}$ and ${ }^{15} \mathrm{~N}$ labelled glycine in $\mathrm{D}_{2} \mathrm{O}$. The signal intensity is satisfactory; the additional delays do not lead to significant losses of polarization for such a small molecule. The main drawback of the method is the impossibility to use the sensitivity enhancement scheme ${ }^{49}$. The linewidth in the indirect $\omega_{1}$ dimension is dominated by field inhomogeneities, as expected from the low-field ${ }^{1} \mathrm{H}$ spectrum (Figure 5). Nevertheless, the resolution was sufficient to observe the line splitting due to the large one-bond scalar coupling ${ }^{1} J_{\mathrm{CC}}=53.5$ $\mathrm{Hz}$ between ${ }^{13} \mathrm{C}_{\square}$ and carboxyl ${ }^{13} \mathrm{C}^{\prime}$ in glycine. This coupling constant corresponds to $15.2 \mathrm{ppm}$ at $0.33 \mathrm{~T}$. The inhomogeneous nature of line broadening at low field was confirmed in a low-field HSQC spectrum (Figure S1), which demonstrates that the proton and carbon-13 resonance frequencies are highly correlated.

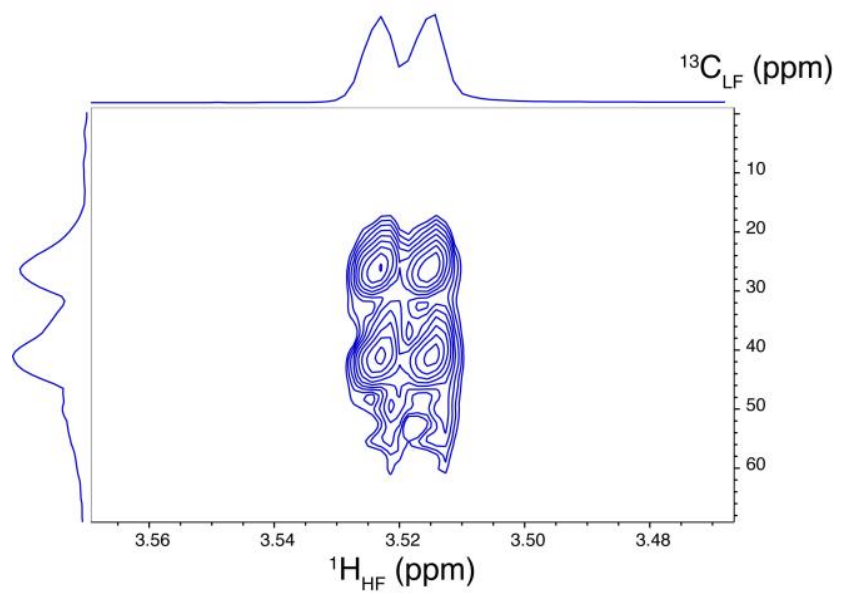

Figure 8. ${ }^{1} \mathrm{H}_{\mathrm{HF}} /{ }^{13} \mathrm{C}_{\mathrm{LF}}-2 \mathrm{~F}-\mathrm{HSQC}$ spectrum of $1 \mathrm{M}$ glycine in $\mathrm{D}_{2} \mathrm{O}$ acquired with the pulse sequence of Figure 7. The scalar coupling ${ }^{1} \mathrm{~J}_{\mathrm{HC}}=4.5 \mathrm{~Hz}$ between the carboxyl ${ }^{13} \mathrm{C}^{\prime}$ and the ${ }^{1} \mathrm{H}$ in glycine leads to a doublet in the horizontal direct $\omega_{2}$ dimension. The homonuclear coupling ${ }^{1} \mathrm{~J}_{\mathrm{CC}}=53.5 \mathrm{~Hz}$ between ${ }^{13} \mathrm{C}^{\alpha}$ and ${ }^{13} \mathrm{C}^{\prime}$ leads to a splitting in the vertical indirect $\omega_{1}$ dimension.

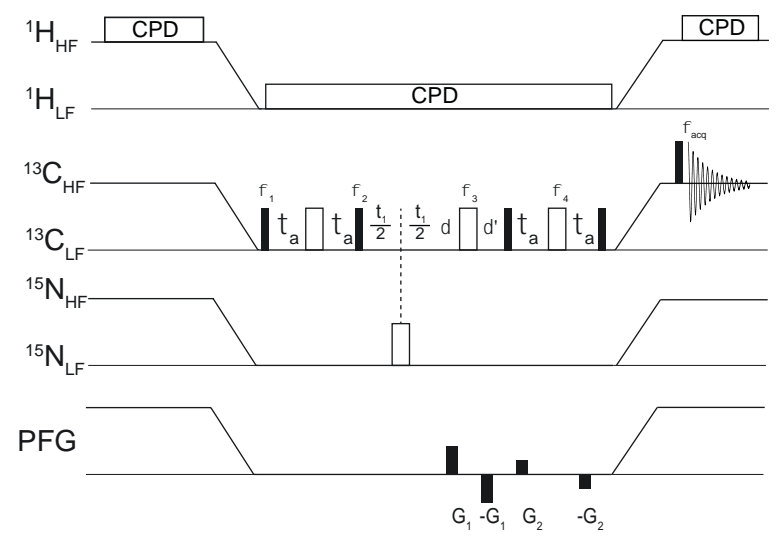

Figure 9. Pulse sequence for 2F-INAZEQUATE. Narrow black and wide-open rectangles represent $90^{\circ}$ and $180^{\circ}$ pulses, respectively. Pulses are applied along the $x$-axis of the rotating frame unless otherwise indicated. The delays are $\tau_{\text {円 }}=1 / 4 \mathrm{~J}_{\mathrm{CC}}=4.7 \mathrm{~ms}, \delta$ and $\delta^{\prime}$ are chosen to obtain an echo for $t_{1}=0$. Composite pulse decoupling was performed with a WALTZ-16 scheme ${ }^{48}$ with $\mathrm{rf}$ amplitudes of $1 \mathrm{kHz}$ on both $\mathrm{HF}$ and LF proton channels. Gradient pulses were applied along the z-axis and had duration of $1 \mathrm{~ms}$ and maximum amplitudes $\mathrm{G}_{1}=4 \mathrm{G} / \mathrm{cm}$ and $\mathrm{G}_{2}=0 \mathrm{G} / \mathrm{cm}$. In the 2F-INADEQUATE variant, $\mathrm{G}_{2}=8 \mathrm{G} / \mathrm{cm}$. The phase cycle was $\phi_{1}=\mathrm{x},-\mathrm{x} ; \phi_{2}=\mathrm{x} ; \phi_{3}=2\{-\mathrm{x}\}, 2\{\mathrm{x}\} ; \phi_{4}=4\{-\mathrm{x}\}, 4\{\mathrm{x}\} ; \phi_{\text {acq }}=\mathrm{x}$, $-x$. Frequency sign discrimination in the indirect dimension was performed with phase alternation of $\phi_{2}$ in a TPPI manner. ${ }^{50}$

\section{The two-field-INAZEQUATE experiment}

To obtain a high-resolution two-field correlation spectrum, the contributions of field inhomogeneities to the linewidth must be significantly reduced. We have demonstrated 42 that this could be achieved in heteronuclear spin systems with the use of zero-quantum coherences. Here we show that highresolution can also be recovered in homonuclear spin systems through the evolution of zero-quantum coherences at low field. Zero-quantum coherences have often been used to obtain high-resolution spectra in inhomogeneous magnetic fields. ${ }^{42,}$ 51-53 We modified the refocused incredible natural abundance double quantum transfer experiment (INADEQUATE) $^{54,55}$ to select zero-quantum coherences at low magnetic field and detect single-quantum coherences at high magnetic field. We dubbed this method 2F-INAZEQUATE (Figure 9).

The 2F-INAZEQUATE and the gradient-selected refocused INADEQUATE experiments are based on the same principles, so only their differences need to be discussed. Most pulses are applied at low field, in order to attenuate off-resonance effects of ${ }^{13} \mathrm{C}$ pulses. The ${ }^{13} \mathrm{C}$ polarization is enhanced during the recovery delay by a steady-state nuclear Overhauser effect ${ }^{56,57}$ obtained by saturating the proton polarisation at high field. The sample is then transferred to the low field where a zeroquantum coherence is excited before the evolution interval $t_{1}$. Scalar couplings between ${ }^{13} \mathrm{C}$ and ${ }^{15} \mathrm{~N}$ are refocused with a single $180^{\circ}$ pulse on the $\mathrm{N}_{\mathrm{LF}}$ channel. The evolution under scalar couplings between ${ }^{13} \mathrm{C}$ and ${ }^{1} \mathrm{H}$ is suppressed by composite pulse proton decoupling. Bipolar pulsed field gradients (noted $\mathrm{G}_{1}$ in Figure 9) are applied at low field after 
the evolution period $t_{1}$. These gradients will defocus all coherences with a non-zero coherence order. Only homonuclear zero-quantum coherences and populations have a non-zero expectation value after these bipolar pulsed field gradients. The delay $2 \tau_{\mathrm{a}}$ is used to convert the desired polarization into in-phase single-quantum coherences $C_{y}$ and selectively refocus the desired components with a bipolar gradient pair $G_{2}$. In the zero-quantum version of the experiment, $\mathrm{G}_{2}=0$; while in the double-quantum version of the experiment, $\mathrm{G}_{2}=2 \mathrm{G}_{1}$. A $90^{\circ}$ pulse on ${ }^{13} \mathrm{C}$ follows to bring the desired polarization along the z-axis for storage during the transfer to high field. At high field, a single $90^{\circ}$ pulse is followed by ${ }^{13} \mathrm{C}$ signal detection. The efficiency of the excitation of zero-quantum coherences relies on the imbalance between the longitudinal ${ }^{13} \mathrm{C}$ polarization of the two nuclei before the first $90^{\circ}$ pulse. Here, the difference in nuclear Overhauser enhancements between the ${ }^{13} \mathrm{C}$ nuclei in the explored molecule was sufficient to ensure the efficient excitation of a zero-quantum coherence. Other approaches, such as the application of selective inversion pulses, may be employed to amplify such an imbalance. Note that a purely high-field INAZEQUATE experiment provides spectra with poor quality as carbon-13 pulses are not broadband at 14.1 T.

The two-field INAZEQUATE experiment provides a correlation between the single-quantum carbon-13 signals in the direct dimension and zero-quantum frequencies in the indirect dimension. The spectra were obtained with a sample of $1 \mathrm{M}$ ${ }^{13} \mathrm{C}$ and ${ }^{15} \mathrm{~N}$ labelled of glycine in $\mathrm{D}_{2} \mathrm{O}$ (Figure 10). The signals in the indirect dimension appear at $131.99 \mathrm{ppm}$, which is close to the difference of $130.99 \mathrm{ppm}$ between the chemical shifts of ${ }^{13} \mathrm{C}^{\alpha} \quad(\delta$ ? $=41.46 \mathrm{ppm})$ and ${ }^{13} \mathrm{C}^{\prime} \quad(\delta$ 目= $172.45 \mathrm{ppm})$. The broadening due to field inhomogeneities are largely suppressed since homonuclear zero-quantum coherences are not affected. The full line-width at half height of the ${ }^{13} C^{\prime}$ signals is $0.11 \mathrm{ppm}$ in the indirect dimension (or $0.39 \mathrm{~Hz}$ ). This resolution is significantly higher than what was achieved in heteronuclear spin systems, where the lowest full line width at half height was of $0.8 \mathrm{ppm}{ }^{42}$. This higher resolution in the twofield INAZEQUATE spectrum is likely do to a combination of factors: (1) the full cancellation of the effect of magnetic field inhomogeneities, (2) the negligible contribution of the chemical shift anisotropy to relaxation at low field and (3) the favourable relaxation properties of zero-quantum coherences in spin systems with dipolar relaxation.
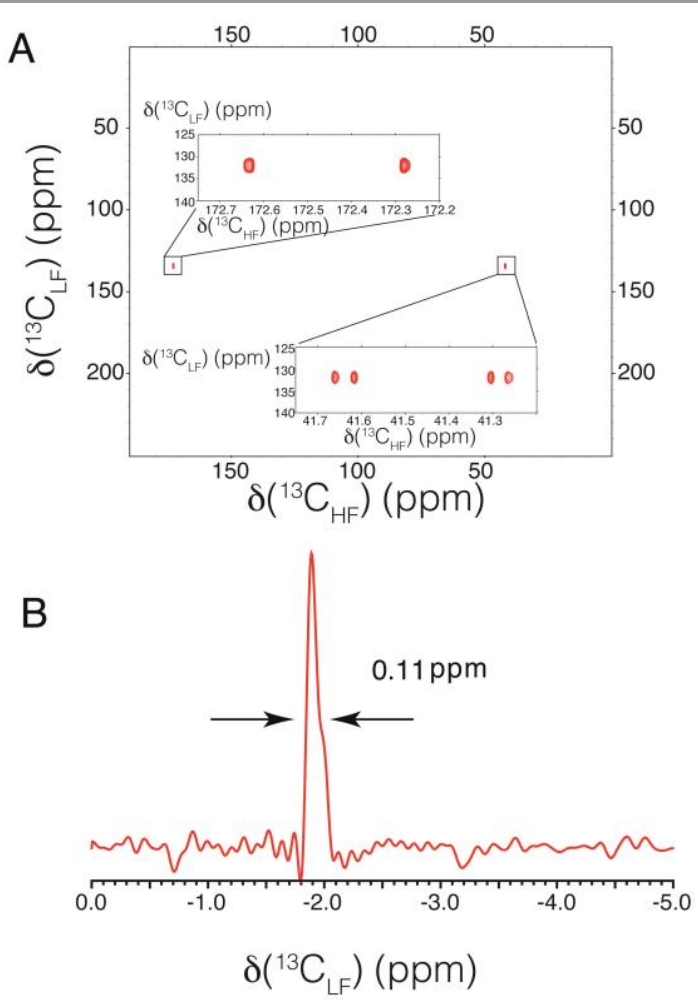

Figure 10. (A) 2D-2F-INAZEQUATE spectrum of $1 \mathrm{M}$ carbon-13 and nitrogen-15 labelled glycine in $\mathrm{D}_{2} \mathrm{O}$. The signals appear at $131.99 \mathrm{ppm}$ in the vertical indirect dimension. (B) 1D spectrum extracted along the vertical dimension (at $41.30 \mathrm{ppm}$ in the direct dimension) of another 2D 2F-INAZEQUATE spectrum obtained with a smaller spectral width to have a higher resolution, with the same pulse sequence and the same pulse lengths. The narrow peak obtained in $B$ is folded many times so the absolute value of the chemical shift is irrelevant.

The comparison of the two-field INAZEQUATE with two-field HSQC and two-field INADEQUATE spectra (Supporting information) illustrates the gain in resolution in the indirect dimension. The two-field INAZEQUATE experiment thus provides a two-field 2D spectrum with high resolution in both dimensions.

Two-field NMR spectroscopy offers the unique opportunity to explore nuclear spin properties at two vastly different magnetic fields. Here, we demonstrate that chemical shifts and scalar couplings can be evaluated from coherent evolution at low magnetic fields in a two-field two-dimensional correlation. This feature has been exploited in our study of a molecule prone to significant chemical exchange ${ }^{42}$. Further work will focus on the investigation of spin systems with more favourable relaxation properties at low field, as well as the efficient control of spin systems allowed by broadband radiofrequency pulses at low field. Currently, the main drawback of two-field NMR is the intrinsic sensitivity of our prototype, which should be improved in future developments. The ability to carry out NMR experiments at several fields will allow NMR spectroscopists to develop a new library of pulse sequences designed to perform different parts of a sequence (polarisation, chemical shift evolution, coherence transfer, etc.) at the most advantageous magnetic field. 


\section{Conclusions}

We have introduced a two-field NMR spectrometer that includes two magnetic centres with different homogenous magnetic fields (14.1 T and $0.33 \mathrm{~T}$ ) combined with a sample shuttle device. The high magnetic field is provided by a standard superconducting NMR magnet, while the second homogenous magnetic field is an engineered plateau in the stray field of the superconducting magnet, with residual inhomogeneities on the order of $10 \mathrm{ppm}$. Both magnetic centres are equipped with triple-resonance probes with z-axis pulsed field gradients. A six-channel NMR console is used to generate $\mathrm{rf}$ pulses. A pneumatic shuttle allows fast sample transport between the two magnetic centres. The pulse sequences for both magnetic centres are conveniently controlled by the software Topspin. We introduce pulse sequences where rf-pulses are applied and evolution under chemical shifts occurs at two fields. Correlation spectra with single- or double-quantum coherences at low field display broad lines in the indirect dimension, because of the fairly crude $10 \mathrm{ppm}$ homogeneity of the low magnetic field. Homonuclear correlations obtained in the 2F-INAZEQUATE experiment, by contrast, feature narrow lines in both dimensions. High-resolution in the indirect dimension is achieved by evolution of homonuclear zero-quantum coherences at low field, which is largely insensitive to line broadening due to moderate magnetic field inhomogeneities. This proof-of-concept experiment demonstrates the feasibility of high-resolution two-field NMR spectroscopy. Two-field NMR can be applied to a host of systems that benefit from low magnetic field, which opens an avenue for novel NMR methods developments.

\section{Acknowledgements}

This work was funded by the European Research Council (ERC) under the European Community Seventh Framework Program (FP7/2007-2013), ERC Grant Agreement 279519 (2F4BIODYN), as well as from the Agence Nationale de la Recherche (ANR-11BS07-031-01).

\section{Notes and references}

1 J. H. Ardenkjaer-Larsen, G. S. Boebinger, A. Comment, S. Duckett, A. S. Edison, F. Engelke, C. Griesinger, R. G. Griffin, C. Hilty, H. Maeda, G. Parigi, T. Prisner, E. Ravera, J. van Bentum, S. Vega, A. Webb, C. Luchinat, H. Schwalbe and L. Frydman, Angew. Chem.-Int. Edit., 2015, 54, 9162-9185.

2 R. R. Ernst, G. Bodenhausen and A. Wokaun, Principles of Magnetic Resonance in One and Two Dimensions, Clarendon Press, Oxford, 1987.

3 J. Cavanagh, W. J. Fairbrother, A. G. Palmer III, M. Rance and N. J. Skelton, Protein NMR Spectroscopy: Principles and practice, Academic Press, San Diego, 2006.

4 P. Schanda, H. Van Melckebeke and B. Brutscher, J. Am. Chem. Soc., 2006, 128, 9042-9043.

5 M. Nowakowski, S. Saxena, J. Stanek, S. Zerko and W. Kozminski, Prog. Nucl. Magn. Reson. Spectrosc., 2015, 9091, 49-73.
6 A. Medek, J. S. Harwood and L. Frydman, J. Am. Chem. Soc., 1995, 117, 12779-12787.

7 L. B. Andreas, T. Le Marchand, K. Jaudzems and G. Pintacuda, J. Magn. Reson., 2015, 253, 36-49.

8 R. Sprangers and L. E. Kay, Nature, 2007, 445, 618-622.

9 J. Fiaux, E. B. Bertelsen, A. L. Horwich and K. Wuthrich, Nature, 2002, 418, 207-211.

10 M. R. Jensen, M. Zweckstetter, J.-R. Huang and $M$. Blackledge, Chem. Rev., 2014, DOI: 10.1021/cr400688u.

11 T. Liu, M. Leskes, W. Yu, A. J. Moore, L. Zhou, P. M. Bayley, G. Kim and C. P. Grey, Science, 2015, 350, 530-533.

12 D. Massiot, R. J. Messinger, S. Cadars, M. Deschamps, V. Montouillout, N. Pellerin, E. Veron, M. Allix, P. Florian and F. Fayon, Acc. Chem. Res., 2013, 46, 1975-1984.

13 L. B. Andreas, M. Reese, M. T. Eddy, V. Gelev, Q. Z. Ni, E. A. Miller, L. Emsley, G. Pintacuda, J. J. Chou and R. G. Griffin, J. Am. Chem. Soc., 2015, 137, 14877-14886.

14 V. Tugarinov, R. Muhandiram, A. Ayed and L. E. Kay, J. Am. Chem. Soc., 2002, 124, 10025-10035.

15 C. Charlier, S. F. Cousin and F. Ferrage, Chem. Soc. Rev., 2016, 45, 2410-2422.

16 M. F. Roberts and A. G. Redfield, FASEB J., 2006, 20, A61A61.

17 D. P. Weitekamp, A. Bielecki, D. Zax, K. Zilm and A. Pines, Phys. Rev. Lett., 1983, 50, 1807-1810.

18 D. B. Zax, A. Bielecki, K. W. Zilm, A. Pines and D. P. Weitekamp, J. Chem. Phys., 1985, 83, 4877-4905.

19 M. P. Ledbetter, T. Theis, J. W. Blanchard, H. Ring, P. Ganssle, S. Appelt, B. Blümich, A. Pines and D. Budker, Phys. Rev. Lett., 2011, 107, 107601.

20 R. Kimmich and E. Anoardo, Prog. Nucl. Magn. Reson. Spectrosc., 2004, 44, 257-320.

21 A. G. Redfield, Magn. Reson. Chem., 2003, 41, 753-768.

22 A. G. Redfield, J. Biomol. NMR, 2012, 52, 159-177.

23 O. Lips, A. E. Privalov, S. V. Dvinskikh and F. Fujara, J. Magn. Reson., 2001, 149, 22-28.

24 F. Noack, Prog. Nucl. Magn. Reson. Spectrosc., 1986, 18, 171-276.

25 K. Modig and B. Halle, J. Am. Chem. Soc., 2002, 124, 1203112041.

26 D. H. Powell, O. M. NiDhubhghaill, D. Pubanz, L. Helm, Y. S. Lebedev, W. Schlaepfer and A. E. Merbach, J. Am. Chem. Soc., 1996, 118, 9333-9346.

27 S. Laurent, L. V. Elst and R. N. Muller, Contrast Media \& Molecular Imaging, 2006, 1, 128-137.

28 Y. Gossuin, Z. Serhan, L. Sandiford, D. Henrard, T. Marquardsen, R. T. M. Rosales, D. Sakellariou and F. Ferrage, Appl. Magn. Reson., 2016, 47, 237-246.

29 S. H. Koenig and R. D. Brown, Prog. Nucl. Magn. Reson. Spectrosc., 1990, 22, 487-567.

30 J. P. Korb, New Journal of Physics, 2011, 13.

31 R. Kimmich and N. Fatkullin, $\mathrm{Nmr}$ - 3d Analysis Photopolymerization, 2004, 170, 1-113.

32 C. Luchinat and G. Parigi, J. Am. Chem. Soc., 2007, 129, 1055-1064.

33 V. N. Sivanandam, J. F. Cai, A. G. Redfield and M. F. Roberts, J. Am. Chem. Soc., 2009, 131, 3420-+.

34 M. W. Clarkson, M. Lei, E. Z. Eisenmesser, W. Labeikovsky, A. Redfield and D. Kern, J. Biomol. NMR, 2009, 45, 217-225.

35 G. Diakova, Y. A. Goddard, J.-P. Korb and R. G. Bryant, Biophys. J., 2010, 98, 138-146.

36 C. Charlier, S. N. Khan, T. Marquardsen, P. Pelupessy, V. Reiss, D. Sakellariou, G. Bodenhausen, F. Engelke and F. Ferrage, J. Am. Chem. Soc., 2013, 135, 18665-18672.

37 J. Leggett, R. Hunter, J. Granwehr, R. Panek, A. J. PerezLinde, A. J. Horsewill, J. McMaster, G. Smith and W. Koeckenberger, PCCP, 2010, 12, 5883-5892. 
38 S. Grosse, F. Gubaydullin, H. Scheelken, H. M. Vieth and A. V. Yurkovskaya, Appl. Magn. Reson., 1999, 17, 211-225.

39 A. S. Kiryutin, A. N. Pravdivtsev, K. L. Ivanov, Y. A. Grishin, H.-M. Vieth and A. V. Yurkovskaya, J. Magn. Reson., 2016, 263, 79-91.

40 C. Y. Chou, M. L. Chu, C. F. Chang and T. H. Huang, J. Magn. Reson., 2012, 214, 302-308.

41 M. Reese, M. T. Turke, I. Tkach, G. Parigi, C. Luchinat, T. Marquardsen, A. Tavernier, P. Hofer, F. Engelke, C. Griesinger and M. Bennati, J. Am. Chem. Soc., 2009, 131, 15086-+.

42 S. F. Cousin, P. Kadeřávek, B. Haddou, C. Charlier, T. Marquardsen, J.-M. Tyburn, P.-A. Bovier, F. Engelke, W. Maas, G. Bodenhausen, P. Pelupessy and F. Ferrage, Angew. Chem. Int. Ed., 2016, 55, 9886-9889.

43 C.-Y. Chou, F. Ferrage, G. Aubert and D. Sakellariou, Scientific Reports, 2015, 5, 12200.

44 M. Reese, D. Lennartz, T. Marquardsen, P. Hofer, A. Tavernier, P. Carl, T. Schippmann, M. Bennati, T. Carlomagno, F. Engelke and C. Griesinger, Appl. Magn. Reson., 2008, 34, 301-311.

452010.

46 G. Bodenhausen and D. J. Ruben, Chem. Phys. Lett., 1980, 69, 185-188.

47 G. A. Morris and R. Freeman, J. Am. Chem. Soc., 1979, 101 760-762.

48 A. J. Shaka, J. Keeler, T. Frenkiel and R. Freeman, J. Magn. Reson., 1983, 52, 335-338.

49 A. G. Palmer, J. Cavanagh, P. E. Wright and M. Rance, J. Magn. Reson., 1991, 93, 151-170.

50 D. Marion and K. Wuthrich, Biochem. Biophys. Res. Commun., 1983, 113, 967-974.

51 D. P. Weitekamp, J. R. Garbow, J. B. Murdoch and A. Pines, J. Am. Chem. Soc., 1981, 103, 3578-3579.

52 L. D. Hall and T. J. Norwood, Journal of the Chemical Society-Chemical Communications, 1986, DOI: 10.1039/c39860000044, 44-46.

53 P. Pelupessy, E. Rennella and G. Bodenhausen, Science, 2009, 324, 1693-1697.

54 A. Bax and R. Freeman, J. Magn. Reson., 1981, 44, 542-561.

55 A. Bax, R. Freeman, T. A. Frenkiel and M. H. Levitt, J. Magn. Reson., 1981, 43, 478-483.

56 D. Neuhaus and M. P. Williamson, The Nuclear Overhauser Effect in Structural and Conformational Analysis, John Wiley \& Sons, New York, 2nd edn., 2000.

57 F. Ferrage, A. Reichel, S. Battacharya, D. Cowburn and R. Ghose, J. Magn. Reson., 2010, 207, 294-303. 